\title{
TASKS DESIGN: A CHALLENGE FOR LANGUAGE TEACHERS
}

\author{
Ramiaida Darmi ${ }^{1 \star}$, Haliza Harun², Rosni Samah ${ }^{3}$, Fariza Puteh-Behak ${ }^{4}$, \\ Noor Saazai Mat Saad ${ }^{5}$, Suraini Mohd $\mathrm{Ali}^{6}$ \\ ${ }^{1}$ Dr., Universiti Sains Islam Malaysia, MALAYSIA, ramiaida@usim.edu.my \\ ${ }^{2}$ Dr., Universiti Sains Islam Malaysia, MALAYSIA, haliza@usim.edu.my \\ ${ }^{3}$ Assoc. Prof. Dr., Universiti Sains Islam Malaysia, MALAYSIA, rosni@usim.edu.my \\ ${ }^{4}$ Dr., Universiti Sains Islam Malaysia, MALAYSIA, fariza@usim.edu.my \\ ${ }^{5}$ Dr., Universiti Sains Islam Malaysia, MALAYSIA, noorsaazai@usim.edu.my \\ ${ }^{6}$ Dr., Universiti Sains Islam Malaysia, MALAYSIA, suraini@usim.edu.my \\ ${ }^{*}$ Corresponding author
}

\begin{abstract}
Creating tasks may sound simple, however, it is one of the challenging jobs for language teachers. In teaching language, teachers need to consider many things such as learners' social background, learner's language proficiency, learners' ability, learners' attitude and many more. Thus, creating tasks can be a challenge for them. Cummins (1981) suggests 2 main elements in designing materials - contextual relevance and cognitive difficulty - which are formed into a matrix to show four levels to consider in tasks design. Based on Cummins' matrix, tasks can be easy for some, and difficult for some. One task may not suit all learners, and thus make task design a challenge for language teachers. This study looks at the use of tasks, developed based on Cummins' matrix, for low proficiency English language learners. Five types of tasks are used, and learners' views are gathered to understand what they think of the tasks. The aim of the study is to explore learners' perceptions towards tasks prepared for an English language class, and aligning them with the teacher's understanding of the tasks. Fourteen learners were involved in the study. Using qualitative approach, data is gathered through interviews, which are then transcribed verbatim, and analysed using thematic analysis. Results show that learners have different views of tasks, which may be due to many factors within learners' experience and knowledge. This shows that although learners are of the same proficiency level, the difficulty of tasks may not be equal for all learners as it is affected by the contextual relevance of the tasks to learners, as well as the cognitive level of learners in their ability to perform the tasks. Therefore, understanding learners is important for teachers in planning suitable tasks for their learners. By doing this, learners will have more enjoyment in language learning, and able to associate tasks more to their life.
\end{abstract}

Keywords: Tasks, contextual relevance, cognitive difficulty, language learning. 


\section{INTRODUCTION}

Tasks design is a part of language teaching and learning. Some people may say that creating tasks is simple, yet, it may be challenging for some language teachers. As each learner is different in his own ways, the language teacher will need to consider many things to suit the learner's differences. Studies on the use of tasks in second language (L2) classroom has been widely researched in the area of second language (L2) teaching. As task-based syllabus aims to facilitate L2 learning (Richards and Rodgers, 2001), it is actively incorporated into language classrooms. According to Richards and Rodgers (2001), it is best to use pedagogical tasks in the classroom as the activities have non-linguistic goal, clear outcome, use any of the four language skills, and convey meaning that reflects real-world language use (Willis \& Willis, 2007). According to Castillo (2008), classroom tasks and materials should be designed to resemble actual use of language for communication, and thus teachers should propose tasks and texts that activate previous knowledge and provide enough background information in order for learners to be able to grasp the key concepts in the tasks.

\subsection{Task-based language teaching}

According to Ellis (2003) and Willis (1996), task-based language teaching (TBLT) is a current approach to L2 teaching that represents a strong version of Communicative Language Teaching. It started in the 1970s when scholars argued that language interaction should teach both grammar and meaning (Skehan, 2003). Ellis (2009) states that task-based approach is beneficial as it offers the opportunity for 'natural' learning inside the classroom, emphasizes meaning over form, provides learners a rich input of target language, is intrinsically motivating and learner-centered, develops communication, and can be used with other approach. According to Ellis (2009), in TBLT, language learning will progress most successfully if teaching aims to create contexts that consider learners' natural language learning ability. This is supported by Samuda and Bygate (2008), who suggest classroom learning to be connected to students" personal experiences, or classroom teaching to be authentic. Because tasks focus on meaning, there is a need for learners to convey information, express an opinion or infer meaning, using their own linguistic and nonlinguistic knowledge in order to complete the activity (Ellis, 2009).

According to Carless (2008), task-based approaches involve a complex teacher role. The tasks must suit the proficiency levels of the students and result in appropriate L2 use (Ellis, 2009). Therefore, teachers need a clear understanding of what a task is, and be involved in the development of the task materials. Studies on tasks have explored a variety of areas such as from a theoretical (language processing) and a methodological (instructional design) perspective (Bygate, Skehan \& Swain, 2001; Ellis, 2000; Foster \& Skehan, 1996; Robinson, 2001; Skehan \& Foster, 1997, 1999; Swain \& Lapkin, 2000; Willis, 1996). However, there are few studies that investigate how tasks need to be designed. According to Castillo (2008), to ensure learners achieve successful L2 learning, teachers should consider learners' background knowledge and include it in the task. This means that teachers should start language teaching by activating learners' background knowledge first. To do this, teachers should not neglect what learners have in their minds so that L2 learning can become a memorable experience for L2 learners (Darmi, 2014). To add, Castillo (2008) considers context and cognitive demands as important elements for teachers to consider when choosing the types of tasks for learners.

\subsection{Contextual support and cognitive demands of tasks}

According to Cummins $(1981,2000)$, there is a relationship between contextual support and cognitive demands in communicative tasks. This is differentiated by the extent to which the meaning being communicated is supported by contextual or interpersonal cues (such as gestures, facial expressions, and intonation present in face-to-face interaction) or is dependent on the amount of information that must be processed immediately through the communicative context (Cummins, 2000, 2001, 2008). Cummins (2008) refers to context as what we bring to a task (internal), and the range of supports that may be incorporated in the task itself (external). Context-embedded communication is more typical of the everyday world outside the classroom, but context-reduced communication reflects tasks with many linguistic demands of the classroom (Cummins, 2008; Darmi, 2014). Cognitively undemanding tasks consist of words that are familiar to learners, and thus require little active cognitive involvement; while cognitively demanding tasks are very open ended and subjective, and require learners to process information (Cummins, 2008; Darmi, 2014).

In cognitively demanding tasks, L2 learners are expected to be fluent in their academic language. They should be able to express and support opinions, formulate hypotheses, propose different solutions, describe, generalize, ask and answer informational and clarifying questions, classify, relate information, compare and contrast, explain cause and effect, interpret, infer, draw conclusions, summarize, evaluate, critique, justify analyze, and persuade (Dutro \& Moran, 2003; Williams, 2001; Zwiers, 2008). This means that they are able 
to use academic language to describe higher order thinking, complexity, and abstraction as clearly as possible. Cummins (1981) proposed a model (Figure 1) for designing tasks based on the range of contextual support and degree of cognitive involvement in communicative activities.

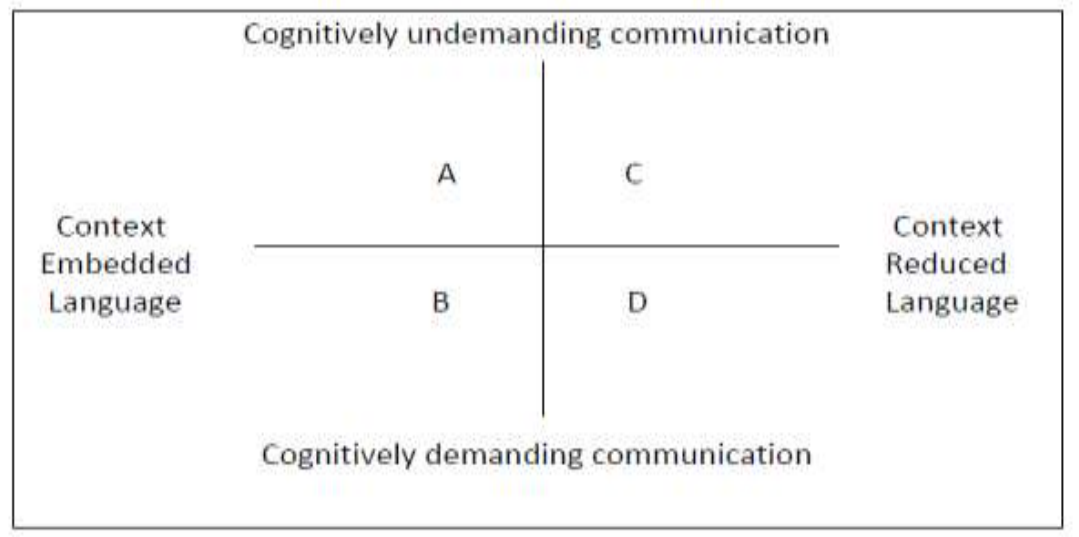

Figure 1: Range of contextual support and degree of cognitive involvement in

The model is represented in four quadrants. Quadrant A involves tasks that reflect face-to-face social conversation i.e. greeting someone. Quadrant B are tasks that require learners to process information based on the contextual support provided i.e. comparing and contrasting, seeking solutions or explaining and justifying. Quadrant C involves tasks that have less contextual support but do not involve learners in too much information processing i.e. listening to a story, copying information from a text and retelling a story. Quadrant $D$ activities require learners to master academic functions (Cummins, 2000) by carrying out tasks that are minimally supported by familiar contextual or interpersonal cues, and require high levels of cognitive involvement for successful task completion i.e. arguing a case, interpreting evidence and evaluating and analyzing critically.

According to Cummins (2001), because some context-embedded activities are clearly just as cognitivelydemanding as context-reduced activities, it is important to distinguish the dimensions of contextualembeddedness and cognitive demand. Learners may have different interpretation of what is contextembedded or cognitively demanding in the tasks, due to the differences in internal attributes such as prior knowledge or interest (Cummins, 1984). The more students know and understand, the easier it is for them to make sense of academic language, since there is internal support for understanding the messages (Garcia, 2009). This is also important for the language teachers as it would help them in designing tasks that are suitable for their learners.

\section{THE STUDY}

Many learners nowadays seem to have limited enjoyment in their learning as many tasks used in the classroom are unsuitable for them. Thus, it is important for teachers to understand the kinds of tasks that they choose or design to be used in their lessons. As teachers, they have to be up-to-date with changes in pedagogy, and also their learners' needs. The aim of this paper is to explore learners' perceptions towards the tasks prepared in the English language class, and aligning them with the teacher's views of the tasks that suit their learners' proficiency level, based on the tasks prepared by them using Cummins' matrix of designing tasks. The data from this study is taken from a bigger study that used quantitative data to look at learners' perceptions on task difficulty in task-based lessons (Darmi, 2016). This study, however, reports part of the qualitative data and links it to teacher's perceptions of the tasks. Therefore, the research questions for the study are:

a. How do learners perceive the tasks prepared in the English language class?

b. How do learners' perceptions of the tasks align with teachers' perceptions of the tasks?

c. How challenging is it for teachers to design tasks in an ESL class?

\section{METHODOLOGY}

Using a qualitative approach, the study involved fourteen learners who participated in an English language class designed for the study, and the researcher as the teacher in the class. Learners worked in pairs in completing the twenty tasks prepared. The tasks are of different task types - jigsaw task (JT), information gap task (IG), problem solving task (PS), decision making task (DM) and opinion exchange task (OE) - each 
constructed in relation to Cummins' (1981) context and cognitive dimensions. There are 4 tasks prepared under each task type, which are labelled as shown in Table 1.

Table 1: Kinds of task types and tasks used in the study

\begin{tabular}{|l|l|l|l|l|l|}
\hline TASK & JT: Jigsaw & IG: Information & PS: Problem & DM: Decision & OE: Opinion \\
TYPES & Task & Gap & Solving & Making & Exchange \\
\hline \multirow{5}{*}{ TASKS } & JT1: Jigsaw & IG1: Room & PS1: Problem & DM1: Menu & OE1: Job \\
& Lion & Layout & Game & Making & Opinion \\
\cline { 2 - 6 } & JT2: Jigsaw & IG2: Spot-the- & PS2: Problem & DM2: Dialogue & OE2: Invention \\
& Clock & difference & Advice & Making & Opinion \\
\cline { 2 - 6 } & JT3: Jigsaw & IG3: Chart & PS3: Teenage & DM3: Gift & OE3: Cultural \\
& Text & Filling & Problem & Decision & Exchange \\
\cline { 2 - 6 } & JT4: Jigsaw & IG4: Rebus & PS4: Career & DM4: Survival & OE4: Language \\
& Play & & Problem & Decision & Exchange \\
\hline
\end{tabular}

Learners were involved in semi-structured pair interviews, which were conducted at the end of the English language class of the study. The interview aimed at gathering learners' perceptions of the tasks used in the language class. This was categorized into the easiest task and the most difficult task, as the researcher wanted to understand how learners' identification of the task difficulty level relate to teacher's perceptions of the tasks difficulty level. This would hopefully provide insights into the variation in contextual support and cognitive demands of the tasks prepared. Interviews were then transcribed verbatim, and analysed using thematic analysis.

\section{RESULTS}

The data on learners' perceptions of task difficulty is discussed in relation to teacher's views of the tasks prepared for their learners. This is to answer research questions 1 and 2. There were seven (7) pairs that responded to the interviews. Each pair' responses in relation to the difficulty or ease of the tasks were categorized according to their perceptions of (1) contextual support and (2) cognitive demands. The following section is divided into two parts: the first part deals with pairs' perceptions of the easiest tasks, and the second part deals with pairs' perceptions of the most difficult tasks.

\subsection{The easiest tasks}

When designing the tasks for the English language class, the teacher had intended the first task (out of the four individual tasks in each task type) to be the easiest. However, result from the interviews show that not all seven (7) pairs shared the teacher's view of the easiest tasks. The rating for the JT group is possibly less reliable since three of the seven pairs did not complete the tasks. Two pairs agreed with the teacher for Jigsaw Task (JT), and three pairs agreed with the teacher for Decision Making (DM) tasks. However, for Opinion Exchange (OE) and Problem Solving (PS) tasks, only one pair viewed the first tasks as the easiest tasks. This disagreement between learners' views of the easiest tasks to teacher's views of the easiest task was also reflected in all pairs for Information gap task, as all seven pairs viewed IG4 as the easiest task. Meanwhile, for each other task type, different pairs viewed different tasks as the easiest task, as reflected in Table 2. This provides evidence of learner variation in their perceptions of the tasks which may be related to the contextual and cognitive factors involved in the tasks.

Table 2: Teacher's vs. Pairs' views of the easiest tasks

\begin{tabular}{|c|c|c|c|c|c|c|c|}
\hline \multirow{2}{*}{$\begin{array}{l}\text { Teacher's views of } \\
\text { the easiest tasks }\end{array}$} & \multicolumn{7}{|c|}{ Pairs' views of the easiest tasks } \\
\hline & $A$ & $B$ & $C$ & D & $E$ & $\mathrm{~F}$ & G \\
\hline JT1 & $\sqrt{ }$ & $\sqrt{ }$ & JT2 & $x$ & $x$ & $x$ & JT4 \\
\hline IG1 & IG4 & IG4 & IG4 & IG4 & IG4 & IG4 & IG4 \\
\hline PS1 & PS2 & PS3 & PS3 & $\sqrt{ }$ & PS3 & $\sqrt{ }$ & PS3 \\
\hline DM1 & V & $\mathrm{v}$ & $v$ & DM3 & DM3 & DM2 & DM3 \\
\hline OE1 & V & OE2 & OE2 & OE1 & OE4 & $x$ & OE2 \\
\hline
\end{tabular}

$X \quad$ : Participants did not complete the task

$\checkmark$ : Pairs' agreement to teacher's views of the easiest tasks

: Pairs' disagreement to teacher's view of tasks \& pairs' view of the easiest task 
Further data from the interviews show the reasons for learners' choice of the easiest task. Some of the interview excerpts to support these findings are provided below.

A majority of learners mentioned that they regarded the task as the easiest task due to its high-context. When tasks are regarded as high-context, learners related them to their everyday life, which is the most frequent association for the easiest tasks. This is shown in interview excerpts 1 below:

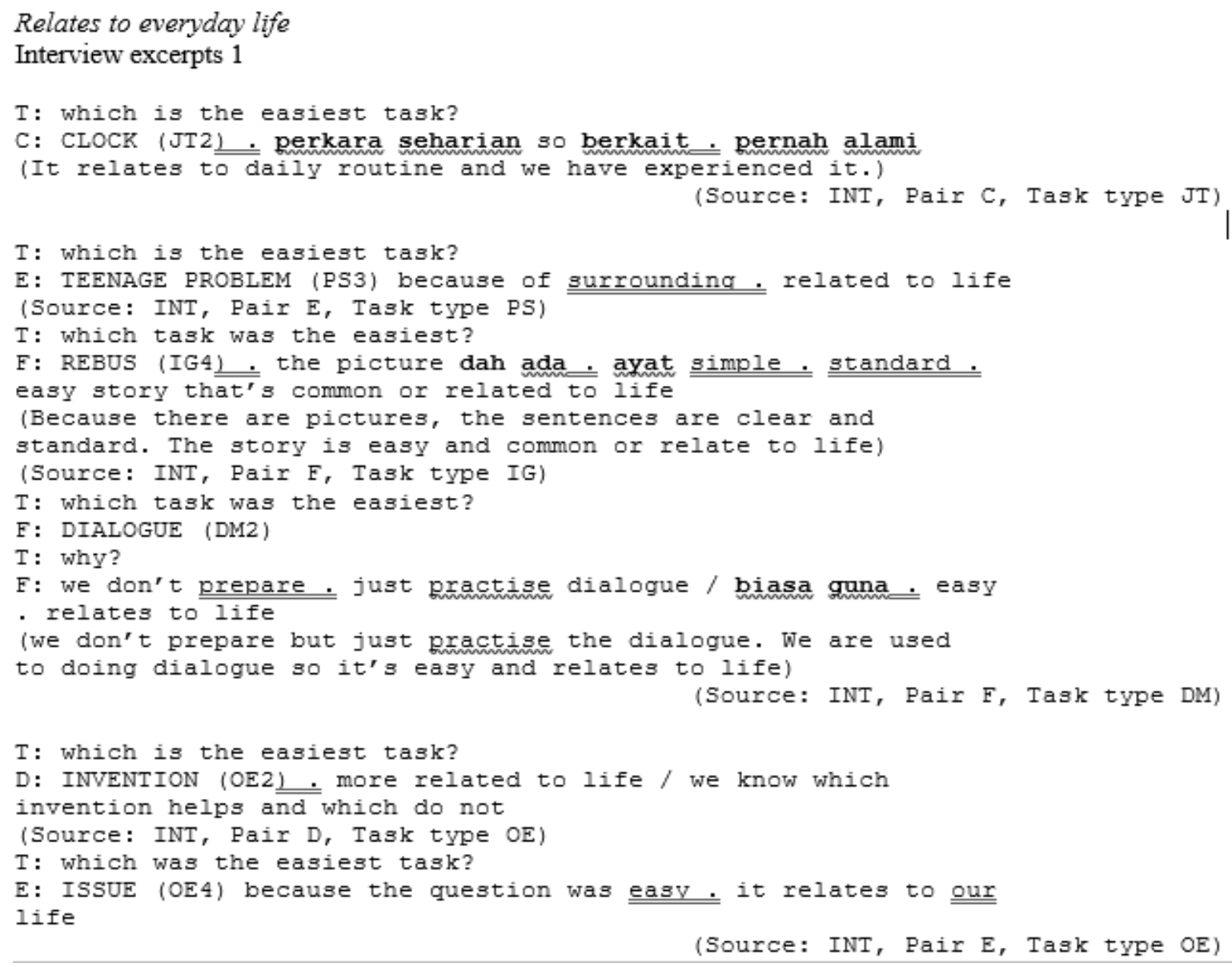

Other than high relevance to context, learners were also able to associate the tasks to their background knowledge. This means that learners are able to relate the tasks to their existing knowledge as they are familiar with the content. Examples of learners' response is shown in interview excerpts 2.

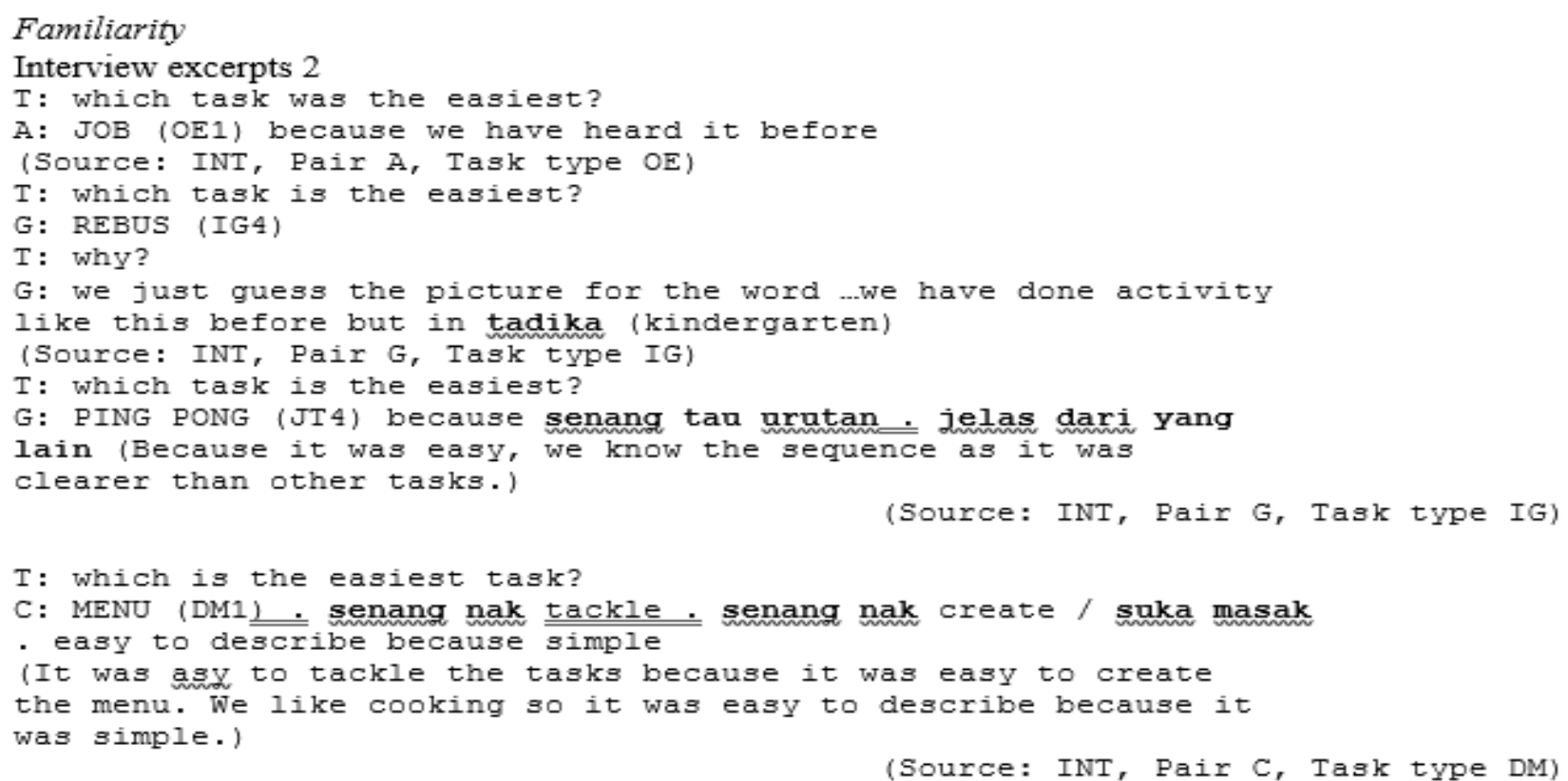


In addition to high relevance to context and background knowledge, a few learners regarded the task as the easiest as the cognitive challenge was low. This was because the tasks did not require them to think indepth to complete the tasks, as clues like pictures were provided in the tasks. Examples of learners' responses to this finding are provided in interview excerpt 3.

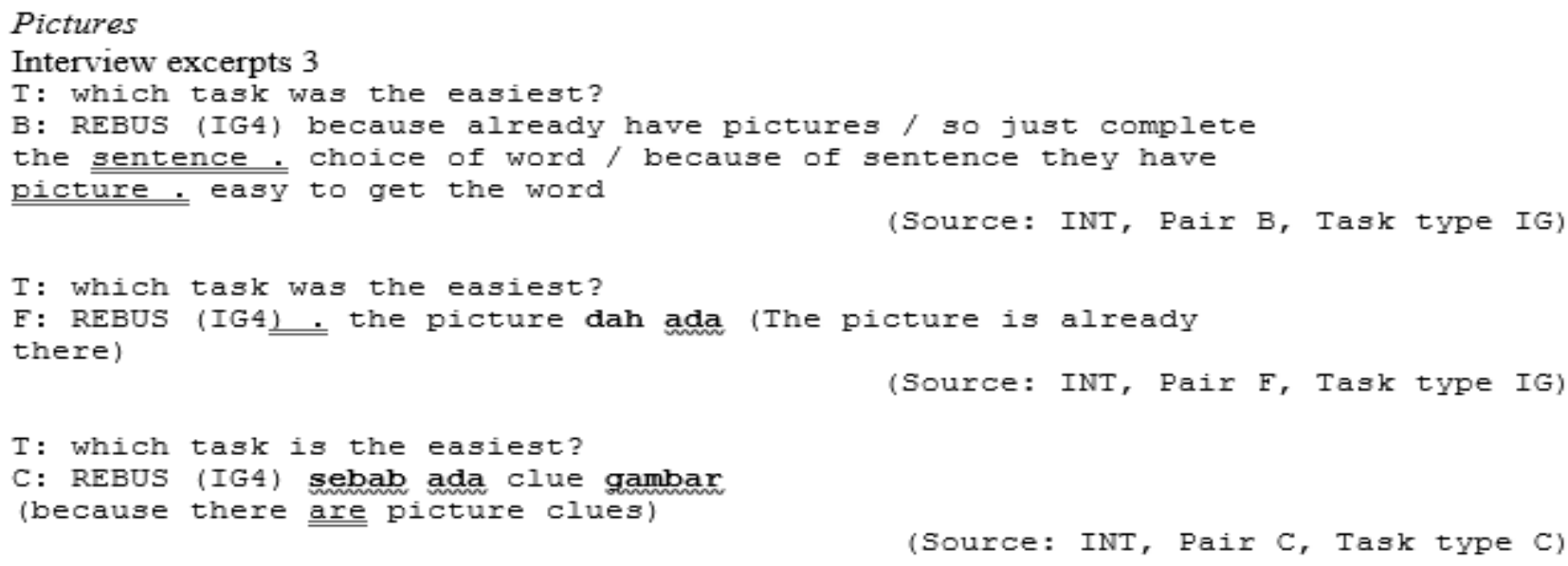

The findings show that pairs' perceptions of the easiest tasks fit closely with Cummins' (1981) contextembedded dimension. However, the data gathered was limited to show a strong link to their perceptions to the low-cognitive challenge of tasks.

\subsection{The most difficult tasks}

Compared to the identification of the easiest task, the teacher designed task 4 of different task types as the most difficult tasks. However, similar to the easiest tasks discussed above, the learners' view of the most difficult tasks did not fully align with the teacher's. From the questions asked in the interviews, I was able to gather learners' reasons for their view of the most difficult task, which allowed me to relate to Cummins' (2008) claim about the influences of task difficulty in language learning. In designing these tasks, the teacher assumed tasks as the most difficult when there was low-contextual support and high-cognitive demand (Darmi, 2013).

There were seven pairs involved in the interviews. However, similar to the data for the easiest tasks, the rating for the JT group is possibly less reliable since three of the seven pairs did not complete the tasks. In designing the tasks, the teacher intended task 4 from each task type to be the most difficult tasks. For Information Gap (IG) task, most learners viewed task 2 as the most difficult. However, there was less consensus among learners for the other four task types. Although one task from each task type dominates others in its group, at least one or more other tasks were also viewed by two or more pairs as the most difficult in all task types. Three pairs viewed PS4; and two pairs viewed OE4 respectively as the most difficult tasks, which are in agreement to the teacher's views of the most difficult task. One pair each viewed JT2, OE1 and DM3 as the most difficult. These findings are summarized in Table 3 below.

Table 3: Teacher's vs. Pairs' views of the most difficult tasks

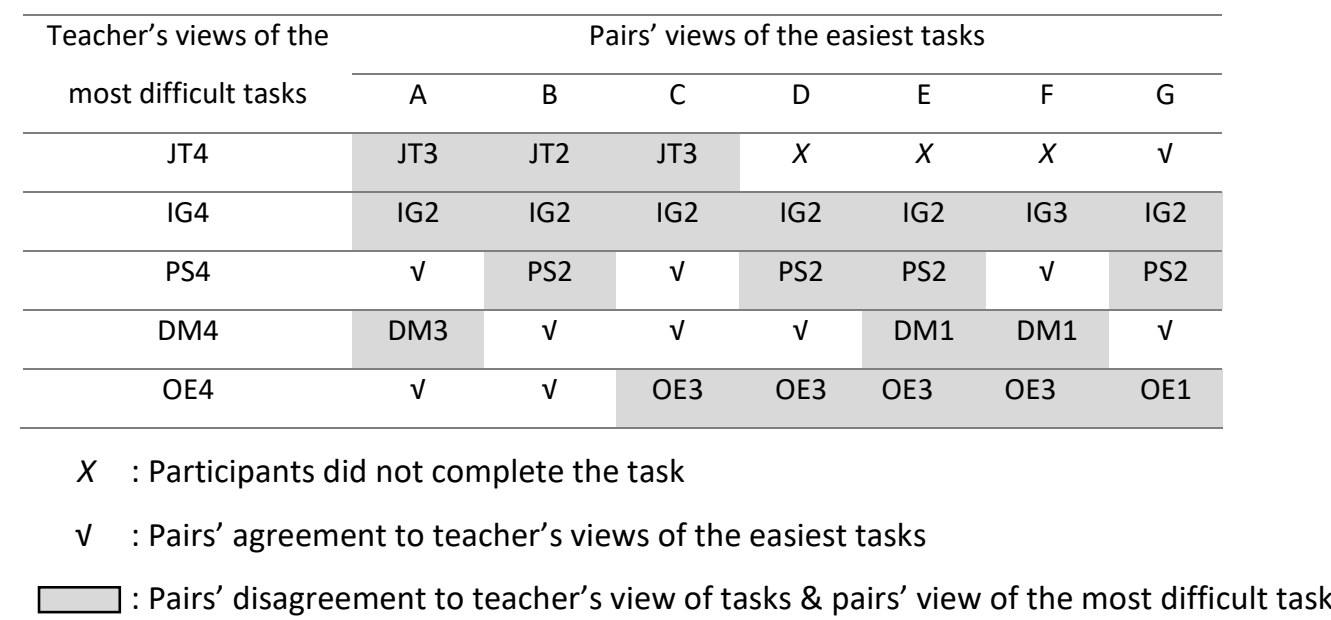


Further data from the interviews show the reasons for learners' choice of the most difficult task. Most of learners' responses for their choice of the most difficult task linked to Cummins' (1981) description of highcognitive demand, while half of the responses linked to reduced contextual support.

Tasks are regarded as highly-cognitive when learners come across unknown English words, and that which involved them in more thinking and the need for use of the $\mathrm{L} 2$ to explain content. This is supported by the learners' responses, as shown in interview extracts 4 and 5.

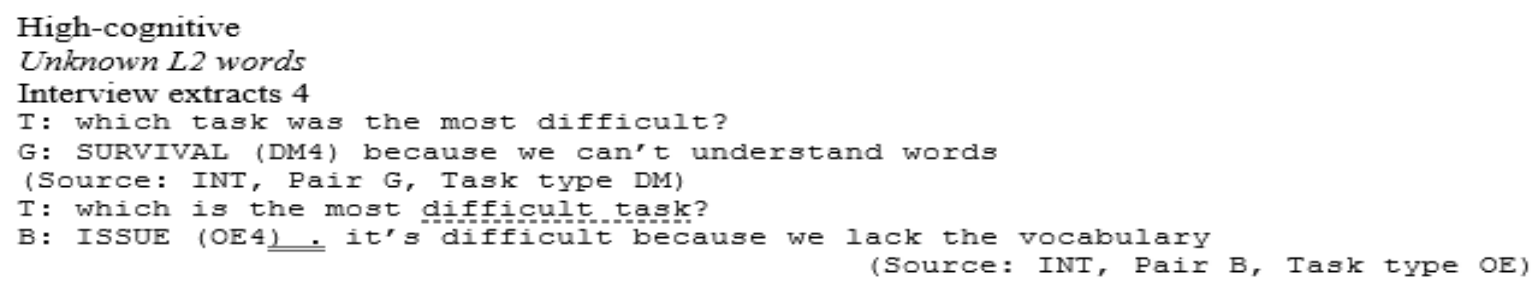

More thinking and confusion

Interview extracts 5

T: which was the most diffichult task?

A: CULTURE $(\mathrm{OE} 3)$. needs more thinking because we don't know much about culture although local culture

(Source: INT, Pair A, Task type OE)

I : which task was the most difficult?

B: CLOCK (JT2). gambar macam tergantung. yang last tu confusing

don't know which picture

(The picture was like incomplete. The last picture was

confusing as we didn't know which picture was to be the last

one.)

(Source: INT, Pair B, Task type JT)

$T$ : which one is the most difficult?

G: SENTENCES (JT3). some sentences were confusing for sequencing

/ last sentence was confusing. ending macam tak ada

(The last sentence was confusing as it seems like there is no

ending.)

(Source: INT, Pair G, Task type JT)

Learners viewed tasks as the most difficult when contextual support is low, and associated to lack of clarity, lack of familiarity with or lack of relation to previous experiences, and no prior experience of the task. The sample responses for learners are provided in the Interview excerpts 7 and 8 below.

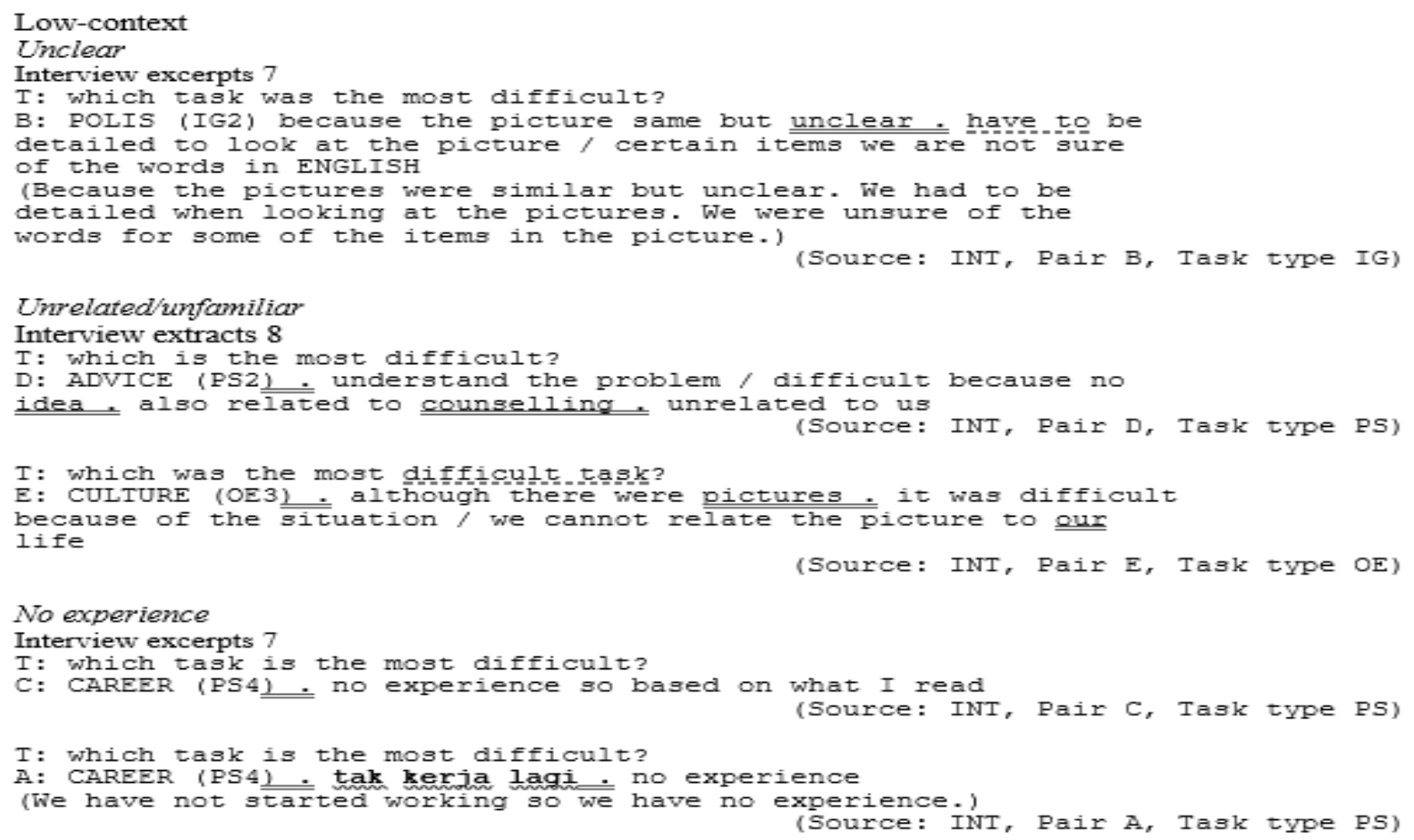


This shows that learners' perception of task difficulty is influenced by both the contextual and the cognitive dimensions. This means that the level of ease of tasks was associated to contextual-embeddedness, and that the cognitive demands played only a minor role.

\subsection{Discussion}

In this section, I compare learners' ratings within task types and the teacher's perceptions of task difficulty, based on how the learners identified the easiest tasks and the most difficult tasks. Figure 2 illustrates learners' perceptions of both levels of task difficulty. These tasks are compared to the teacher's perceptions of the tasks in Cummins' (1981) matrix. This discussion reports data gathered for research question 2 . This is shown in Figure 2.

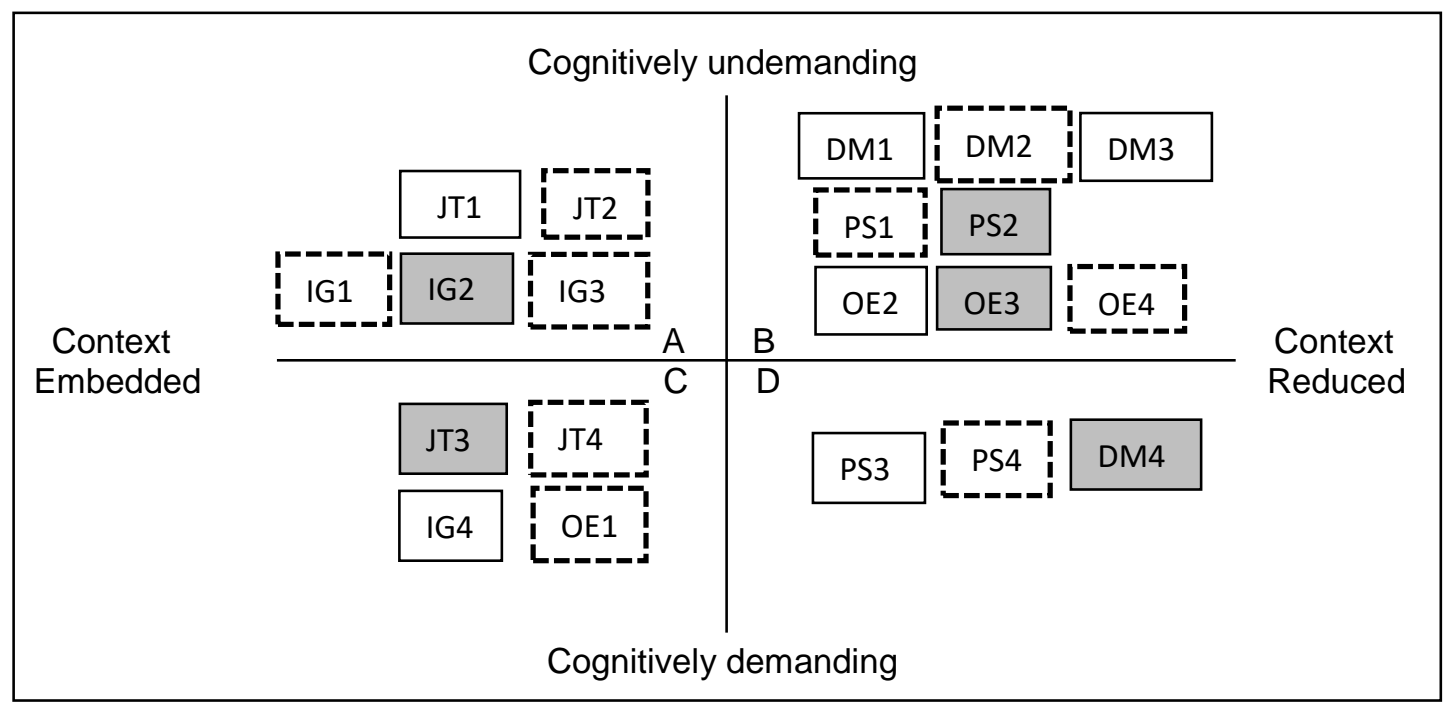

Figure 2: Learners' perceptions of task difficulty in relation to Cummins' (1981) matrix

\begin{tabular}{l} 
Tasks (in each type) identified by most pairs as the easiest \\
Tasks (in each type) identified by most pairs as the most difficult \\
\hline
\end{tabular}

In Figure 2, we see that pairs' perceptions of the easiest and the most difficult tasks occur all over the matrix, showing no relationship between overall relationships between task difficulty and the contextual support and cognitive demands of tasks. When learners' interpretation of task difficulty is compared to that of the teacher's, we see that the result differs. As mentioned earlier, the teacher's perceptions of task difficulty were based on Cummins' (1981) framework, and the learners' perceptions of task difficulty was based on their view of the easiest and the most difficult task of each task type. Based on Cummins' (1981) matrix, the easiest tasks would be within quadrant $A$, while the most difficult task would be within quadrant D. However, the findings show that although the teacher's perception of the difficulty of the tasks connects to learners' perceptions in most ways, the variability in learners' perceptions of task difficulty shows that the teacher's judgement may not always match that of the learners. This links to research questions 3 , which shows the variability of external factors - contextual support and cognitive demands - that teachers need to think of when designing tasks in the ESL class. Learners' comments in the interviews presented earlier provide further understanding of how they interpret the tasks. The easiest tasks are associated to tasks that they can relate to their everyday life, tasks that are familiar to them, and tasks that provide clues such as pictures to guide them to complete the tasks. While for the most difficult tasks, learners relate them to tasks that contain words that they do not know, require them to do more thinking, unclear, unrelated or unfamiliar, and that they have not experienced. This data shows that there is a connection between the easiest task and contextual support, and the most difficult task with cognitive demands, which links to learners' perceptions of the level of task difficulty in providing a dominant connection between both contextual support and cognitive demands.

\section{CONCLUSIONS}

Results show that learners have different views of tasks, which may be due to many factors within learners' experience and knowledge. This shows that although learners are of the same proficiency level, the difficulty 
of tasks may not be equal for all learners as it is affected by the contextual relevance of the tasks to learners, as well as the cognitive level of learners in their ability to perform the tasks. The way that learners in this study perceived the easiest and the most difficult tasks allowed me to understand how they viewed the level of difficulty of tasks, which enabled me to link to other studies on task difficulty (Robinson, 2001; Tavakoli, 2009; Tavakoli \& Skehan, 2005). These researchers have identified lack of familiarity with task types, the cognitive demand of the tasks, the clarity of pictures or story and the amount of information as factors that contribute to task difficulty and easiness.

The findings have also revealed that the teacher and the learners may have similar interpretation of tasks, but that there is a higher possibility of differences in perceptions as learners are different in their own ways, which makes it complex for teachers to design exactly the same tasks to suit all learners in the same class. It is also important to highlight the differences that was found between the teacher's and the learners' perception of task difficulty. Although there is a mismatch among their perceptions within tasks and among task types, the teacher's and the learners' perceptions seem to show some connection: the easiest tasks were linked to context-embedded and cognitively demanding and undemanding tasks, while the most difficult tasks were linked to context-reduced and cognitively demanding tasks. This shows differences in the learners' and teacher's interpretation of the cognitive and contextual level of the tasks. This finding generally shows that a teacher's perception of task difficulty 'may not always match those of the learners'.

\section{REFERENCE LIST}

Bygate, M., Skehan, P, \& Swain, M. (2001). Researching pedagogic tasks, second language learning, teaching and testing. Harlow, UK: Longman.

Carless, D. (2008). Implementing task-based learning with young learners. ELT Journal, 56 (4), $389-396$.

Castillo, R. (2008). Issues involved in context, comprehension and content. Latin American Journal of Content and Language Integrated Learning, 1 (1), 15-25.

Cummins, J. (2008). BICS and CALP: Empirical and theoretical status of the distinction. In B. A. Street, Encyclopedia of Language and Education, (2nd ed.).(Vol. 2: Literacy, pp. 71-83). New York: Springer Science + Business Media LLC.

Cummins, J. (1984). Bilingualism and special education: Issues in assessment and pedagogy. San Diego, CA: College Hill Press.

Cummins, J. (2000). Language, power and pedagogy: Bilingual children in the crossfire. Great Britain.: Multilingual Matters Ltd.

Cummins, J. (2001). Negotiating identities: Education for empowerment in a diverse society (2nd ed.). Los Angeles, CA: California Association for Bilingual Education.

Cummins, J. (1981). The role of primary language development in promoting educational success for language minority students. In C. S. (Ed.), Schooling and language minority students: A theoretical framework. Los Angeles: Evaluation, Dissemination and Assessment Center.

Darmi, R., Harun, H., Samah, R., Puteh-Behak, F., Mat Saad, N.S. \& Mohd Ali, S. (2016). Learners' perceptions on task difficulty in task-based lessons. In International Conference on Education and Regional Development 2016 (ICERD 2016) Proceeding. Universiti Pendidikan Indonesia, Bandung, Indonesia, pp. 686-696

Darmi, R. (2014). The Effects of the Application of Cummins' Model on Learners' Language Use. In International Journal of Language Education and Applied Linguistics, Vol. 1, 1-8, Penerbit Universiti Malaysia Pahang (ISSN: 2289-7208 print).

Darmi, R. (2013). Exploring teacher-learner perceptions of first language use and tasks, and their relationship to task types and task difficulty in a Malaysian tertiary context. Phd Thesis. La Trobe University, Melbourne.

Dutro, S. \& Moran, C. (2003). Rethinking English language instruction: An architectural. In G. G. (Eds.), English learners: Reaching the highest level of (pp. 227-258). Newark, DE: International Reading Association.

Ellis, R. (2009). Task-based language teaching: sorting out the misunderstandings. International Journal of 
Applied Linguistics, 19 (3), 1-26.

Ellis, R. (2003). Task-based language teaching and learning. Oxford, UK: Oxford University Press.

Ellis, R. (2000). Task-based research and language pedagogy. Language Teaching Research, 4, 193-220.

Foster, P. \& Skehan, P. (1996). The influence of planning and task type on second language performance. Studies in Second Language Acquisition, 18, 299-323.

Garcia, O. (2009). Bilingual education in the 21st century a global perspective.Singapore: Wiley-Blackwell.

Richards, J. \& Rodgers, T. S. (2001). Approaches and methods in language teaching (2nd Ed.). Cambridge, UK: Cambridge University Press.

Robinson, P. (2001). Task complexity, task difficulty, and task production: Exploring interactions in a componential framework. Applied Linguistics, 22 (1), 27-57.

Samuda, V. \& Bygate, M. (2008). Tasks in second language learning. New York: Palgrave Macmillan.

Skehan, P. \& Foster, P. (1997). Task type and task processing conditions as influences on foreign language performance. Language Teaching Research, 1 (3), 185-211.

Skehan, P. \& Foster, P. (1999). The influence of task structure and processing conditions on narrative retellings. Language Teaching Research, 49, 93-120.

Skehan, P. (2003). Task-based instruction. Language Teaching, 36, 1-14.

Swain, M. \&. Lapkin, S. (2000). Task-based second language learning: The uses of the first language. Language Teaching Research, 4 (3), 251-274.

Willis, J. (1996). A framework for task-based learning. Harlow, Essex: Addison Wesley Longman. Longman.

Willis, D. \& Willis, J. (2007). Doing task-based teaching. Oxford: Oxford University Press.

Zwiers, J. (2008). Building academic language: Essential practices for content. Newark, DE: International Reading Association. 